\title{
Ethical Rules Concerning Studies and Publication of Results
}

DOI: $10.1134 / \mathrm{S} 1061934810070014$

From time to time, the world's scientific journals reveal cases of plagiarism, falsification of the results of experiments, duplication of publications, and other breaches, to say nothing of mentioning "honest" errors, which result from a perfunctory, thoughtless attitude to studies. Some facts have appeared even in mass media publications.

Here, I have included several examples. Hiroaki Kawasaki, a researcher from Tokyo University described the results of an experiment he evidently did not perform. His supervisor Professor Kazunari Taira trusted his colleague, and papers with nonexistent results concerning DNA were published in a number of journals, including Nature. Soon, it became clear that the evidence does not exist. It is worth noting that Tokyo University did not stand up for its researchers and both have been dismissed.

Science has withdrawn the already published paper by German chemist J.H. Schön with coauthors and that by Korean researcher Woo-Suk Hwang with a large group of coauthors. Another Japanese researcher, Akio Sugino, from the University of Osaka, had published a paper with falsified and "corrected" data, also about DNA, in the Journal of Biological Chemistry. The university has dismissed Sugino.

P. Dasgupta, a well-known American analyst, discovered that one Indian group publishes the same results in several journals, including in our Zhurnal Analiticheskoi Khimii. The university where the group worked has taken measures.

Of interest are publication rules developed by the American Chemical Society. These rules are periodically updated and published; these were also published in Russian [1]. The last version can be found in Analytical Chemistry [2]. As in the previous versions, these rules give separate recommendations to editors of scientific journals, authors of papers, and referees; in addition, requirements for popular scientific or journalistic papers are formulated.
Japanese journal Analytical Sciences has recently published ethical guidelines for its authors [3]. Below, I present fragments of these rules.

"Duplication of publications. It is also unethical for authors to submit multiple similar studies for publication at the same time. It is unethical for authors to submit a manuscript that has already been published or in the process of review elsewhere. Excessive fragmentation of the author's work into multiple manuscripts is also not accepted. Submission of a full paper following the author's preliminary work is permitted only when the journal's editor is properly informed at the stage of submission of the publication.

Reproducibility, plagiarism, and falsification. Authors must report their work accurately and precisely in order to be reproduced by other researchers independently. Plagiarism and falsification in any part of the submitted paper are serious offenses in the scientific community and must be strictly avoided. Authors are also requested to provide proper references associated with their work, including the authors' relevant previous works published elsewhere.

Authorship. The coauthors should be limited to those who have sufficiently contributed to the content of the work in a responsible and accountable manner. That corresponding author must confirm that the submission of the manuscript has been approved by all coauthors. The author's name will appear in the paper as is written in the submitted manuscript. No changes in the list of the authors are acceptable in the processes of revision and proofreading without permission by the journal's editor."

\section{REFERENCES}

1. Zhurn. Analit. Khim., 1988, vol. 43, no. 1, p. 183.

2. Anal. Chem., 2008, vol. 80, no. 1, p. 36 .

3. Anal. Sci., 2009, vol. 25, no. 10, p. 1269.

Yu. A. Zolotov 